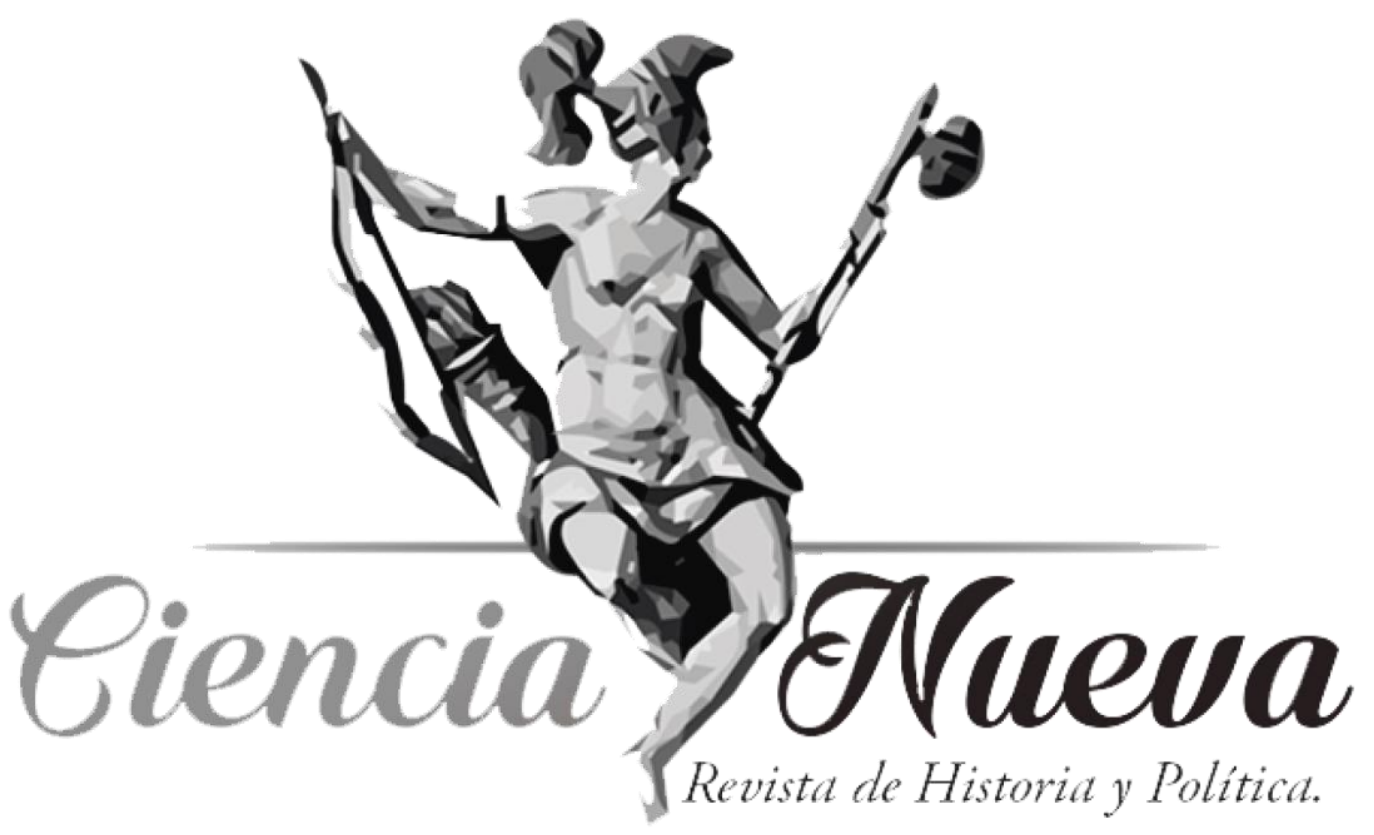

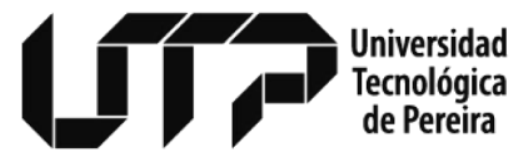

Maestría en Historia

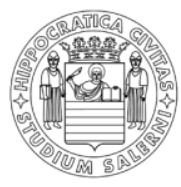

UNIVERSITÀ DEGLI STUDI DI SALERNO

Maestría en Ciencia Política

DOSSIER

Dr. Luis Ervin Prado Arellano, Editor invitado

\title{
LA RENTA DE AGUARDIENTE DURANTE EL PROCESO DE INDEPENDENCIA DE LA NUEVA GRANADA, 1810-1819
}

THE INCOME OF SUGAR CANE ALCOHOL DURING THE INDEPENDENCE PROCESS OF THE

NEW GRANADA, 1810-1819

DOI: https://doi.org/10.22517/25392662.22911

Roger Pita Pico

pp. $105-122$

Vol. 3 Núm. 2 | Julio-Diciembre de 2019

Pereira, Colombia 


\section{LA RENTA DE AGUARDIENTE DURANTE EL PROCESO DE INDEPENDENCIA DE LA NUEVA GRANADA, 1810-1819*}

\section{THE INCOME OF SUGAR CANE ALCOHOL DURING THE INDEPENDENCE PROCESS OF THE NEW GRANADA, 1810-1819}

Roger Pita Pico ${ }^{* *}$

rogpitc@hotmail.com

ORCID: http://orcid.org/0000-0001-9937-0228

$\begin{array}{cc}\text { Recibido: } & 07 \text { de septiembre de } 2019 . \\ \text { Revisado: } & 12 \text { de noviembre de } 2019 . \\ \text { Aceptado: } & 26 \text { de noviembre de } 2019 . \\ \text { Publicado: } & 30 \text { de diciembre de } 2019 .\end{array}$

\section{Resumen}

En el marco de la conmemoración del Bicentenario de la Independencia de las Naciones Hispanoamericanas, el objetivo de este artículo se centra en analizar la renta del aguardiente durante el proceso de independencia en el periodo comprendido entre 1810 y 1819 en la Nueva Granada, observando en detalle la forma como la guerra afectó esta renta y el respaldo económico derivado de las utilidades de este rubro en el sostenimiento de la tropa y en otros sectores. Adicionalmente, se pretende examinar los avances y las vicisitudes, así como también los cambios y permanencias en el manejo de este ramo de la economía que osciló entre el monopolio estatal y la liberalización durante cada una de las fases de este periodo de convulsión política y militar de la lucha por la emancipación.

Palabras clave: aguardiente, comercio, economía, Independencia, Colombia, siglo XIX.

\begin{abstract}
Within the framework of the commemoration of the Bicentennial of the Independence of the Latin American nations, the objective of this article is to analyze the income of sugar cane alcohol during the process of independence in the period between 1810 and 1819 in New Granada, observing in detail the way in which war affected this income and the economic support derived from the profits of this item in the support of the troops and in other sectors. Additionally, it is intended to examine the advances and vicissitudes, as well as the changes and permanence in the management of this branch of the economy that oscillated between the state monopoly and liberalization during each phase of this period of political and military upheaval of the fight for emancipation.
\end{abstract}

Keywords: sugar cane alcohol, trade, economy, Independence, Colombia, 19th century.

\footnotetext{
* Este documento respeta las directrices y normas dispuestas en la Declaración de Ética de Publicación de Ciencia Nueva, Revista de Historia y Política. Esta declaración puede consultarse en la página web de la revista: http://revistas.utp.edu.co/index.php/historia

** Politólogo de la Universidad de Los Andes con opción en Historia; Especialista en Gobierno Municipal, Especialista en Política Social y Magíster en Estudios Políticos de la Pontificia Universidad Javeriana. Director de la Biblioteca Eduardo Santos de la Academia Colombiana de Historia.
} 


\section{Introducción}

$\mathrm{E}$ l aguardiente, al igual que el guarapo y la chicha, fue una bebida autóctona consumida en la Nueva Granada ${ }^{1}$ desde el periodo de dominio hispánico. La fabricación del aguardiente era con base en la fermentación de la caña de azúcar, producto cultivado en amplias zonas cálidas y templadas.

La producción y venta ilícita del aguardiente se inició en 1673 hasta que, tras avizorar beneficios rentísticos y bajo el marco de la reestructuración del sistema fiscal americano promovido por las reformas borbónicas, el gobierno español instauró en 1736 el estanco, con lo cual emprendió una campaña de represión en contra del consumo de aquellas otras bebidas artesanales. El primer sistema que estuvo en funcionamiento hasta 1749 fue el de arriendo por remate, después de lo cual se abrió paso al sistema de asientos. Desde 1760, los beneficios rentísticos del negocio motivaron al virrey José Solís a establecer la administración directa a través de funcionarios reales que ejercían un control más directo y efectivo a la producción y distribución con la instalación de fábricas y estancos en algunas regiones ${ }^{2}$.

La presión ejercida por el establecimiento de los estancos y las fuertes cargas fiscales provocaron un gran impacto en los sectores productivos y generaron un descontento popular que se vio reflejado en la revuelta comunera surgida en la provincia del Socorro hacia 1781, los amotinados manifestaron la ira derramando el aguardiente en algunas oficinas del ramo ${ }^{3}$. Aunque en las capitulaciones los insurrectos propusieron una reducción en las tarifas de las contribuciones sobre el tabaco y el aguardiente, ninguna de estas expectativas fue cumplida por el gobierno virreinal que emprendió una fuerte represión contra los líderes comuneros ${ }^{4}$.

Años después se dio una apertura en el mercado que propició la entrada masiva de vinos españoles, con lo cual se afectó en gran medida la venta de aguardiente, la actividad en los trapiches y la vinculación de mano de obra esclava a estos centros de producción. Sin embargo, aún en los años finales del siglo XVIII el ramo seguía suministrando aportes importantes a las arcas oficiales, pues en el periodo comprendido entre 1796 y 1800 se obtuvieron más de 1.400 .000 pesos $^{5}$.

Por estos años, seguía intenso el debate sobre la disyuntiva de mantener el estanco o liberalizarlo. Uno de los que participó en esta discusión fue José Ignacio de Pombo, quien en un informe presentado el 18 de abril de 1807 al Consulado de Cartagena, advirtió sobre los beneficios que implicaba no colocar trabas impositivas al libre fomento de la agricultura, y denunció los efectos negativos del estanco en la economía, para lo cual expuso como ejemplo la experiencia vivida en Estados Unidos y Francia ${ }^{6}$.

La crisis política iniciada en España en 1808 tras la prisión del rey Fernando VII y la invasión de los franceses generó un vacío en el poder y marcó el inicio del período revolucionario experimentado en los dominios hispanoamericanos. Esta etapa

\footnotetext{
${ }^{1}$ La Nueva Granada correspondía en tiempos del dominio hispánico a lo que hoy se conoce como República de Colombia.

${ }^{2}$ Gilma Lucía Mora de Tovar, “Chicha, guarapo y presión fiscal en la sociedad colonial del siglo XVIII”, Anuario Colombiano de Historia Social y de la Cultura, n. ${ }^{\circ}$ 16-17 (1988): 22.

${ }^{3}$ Biblioteca Nacional de Colombia (BNC), Fondo Manuscritos, tomo 371, ff. 1r-80v.

${ }^{4}$ John Leddy Phelan, La revolución comunera en Colombia, 1781 (Bogotá: Universidad del Rosario, 2009), 303.

${ }^{5}$ Germán Colmenares (Comp.), Relaciones e Informes de los Gobernantes de la Nueva Granada, tomo III (Bogotá: Biblioteca Banco Popular, 1989), 127.

${ }^{6}$ Archivo Histórico Restrepo, Fondo XIII, vol. 18, ff. 1r-8v.
} 
independentista comenzó en la Nueva Granada en 1810 con un primer experimento republicano que se extendió hasta 1815 cuando los españoles restauraron el poder político y militar en lo que se conoció como el periodo de Reconquista. En agosto de 1819 los republicanos finalmente recuperaron el poder político ${ }^{7}$.

Tras el inicio del proceso de independencia se registró un inusitado incremento en los precios del aguardiente ${ }^{8}$ y un crecimiento en el ingreso de licores extranjeros como el ron y la champaña, al tiempo que se multiplicaban los casos de fraude ${ }^{9}$ y contrabando. Paradójicamente, mientras disminuía el consumo de aguardiente en la comunidad, durante la guerra aumentó tanto al interior del ejército patriota como del ejército realista, ya que esta bebida fue incorporada en la dieta diaria de las tropas en campaña, siendo un incentivo adicional al igual que lo era el suministro de tabaco. Su objetivo era infundir aliento a la tropa con el fin afrontar los rigores de la guerra e incluso como paliativo para algunos males del cuerpo $^{10}$.

La mayoría de los estudios sobre la renta de aguardiente en la Nueva Granada hacen alusión al periodo de dominio hispánico y recientemente han sido publicados algunos trabajos sobre la segunda mitad del siglo XIX y el siglo XX. En vista de los vacíos existentes, y en el marco de la conmemoración del Bicentenario de la Independencia de las Naciones Hispanoamericanas, el objetivo de este artículo se centra en analizar la renta del aguardiente durante el proceso de independencia entre 1810 y 1819 en la Nueva Granada. Es decir, durante la primera República Federativa y la fase de Reconquista, observando en detalle la forma como la guerra afectó esta renta y el respaldo económico derivado de las utilidades de este ramo en el sostenimiento de la tropa y en otros sectores. Adicionalmente, se pretende examinar los avances y las vicisitudes, así como también los cambios y permanencias en el manejo de este ramo de la economía que osciló entre el monopolio estatal y la liberalización durante cada una de las fases de este periodo de convulsión política y militar de la lucha por la emancipación.

\section{La renta: afectaciones y solidaridad económica}

El estado deficitario del ramo de aguardiente se profundizó con la llegada del periodo de independencia. El nivel de tensión política y de confrontación militar, agravado en ocasiones con manifestaciones de caos y anarquía, causó estragos en la economía y desde luego la renta de aguardiente no fue la excepción. El impacto del juego de retaliaciones y represiones se sintió no solo en las siembras de caña de azúcar y en las instalaciones de las fábricas, sino también en los empleados y en las finanzas mismas del negocio. Por lo general, la sede de la renta de aguardiente era, junto con la iglesia y las oficinas públicas, el blanco preferido de los ataques y los saqueos.

\footnotetext{
${ }^{7}$ El Congreso de Angostura expidió el 17 de diciembre de este año la Ley Fundamental que dio nacimiento a la República de Colombia como resultado de la unión de los departamentos de Venezuela, Quito y Nueva Granada. Ley Fundamental de la República de Colombia (Angostura: [s.n.], 1819).

${ }^{8}$ Una generalizada carestía de varios productos percibió el cronista José María Espinosa en la ciudad de Santa Fe en enero de 1810. Entre ellos estaba el aguardiente, habiendo subido el precio de cada botella a 6 reales. José María Caballero, Particularidades de Santa Fe (Bogotá: Biblioteca Popular de Cultura Colombiana, 1946), 59.

${ }^{9}$ En 1779 el gobierno español dictó un reglamento normativo para combatir los casos de fraude. Archivo Histórico Cipriano Rodríguez Santa María (AHCRSM), Universidad de la Sabana, Fondo Manuel María Mosquera, caja 3, carpeta 3, ff. 17r-81v.

${ }_{10}$ Véase: Roger Pita Pico, "El consumo de bebidas embriagantes durante el proceso de Independencia de Colombia: aliento, festejo y conspiración”, Historia y Memoria, n. 7 (2013): 235-253.
} 
El 4 de noviembre de 1810, Manuel de Olaya junto con un grupo de ciudadanos se alzó en contra del cabildo y las autoridades españolas de la ciudad de Iscuandé en la Costa Pacífica y constituyeron una junta provisional revolucionaria. Una de sus primeras acciones fue apoderarse de la administración, los estancos de aguardiente y tabaco, la fábrica de pólvora y otras oficinas públicas ${ }^{11}$.

A mediados de junio de 1819, los mandos oficiales españoles denunciaron que una partida de guerrillas patriotas había asesinado al oficial Arévalo, quitándole dos cargas de dinero y un cargamento de aguardiente que iba dirigido a las tropas realistas acantonadas en Sogamoso $^{12}$.

Prisiones, destierros, confiscaciones, ejecuciones y otra serie de represiones debieron afrontar los empleados del ramo en estos tiempos de tensiones, odios y venganzas. Tras la restauración del gobierno monárquico en 1816, se presentó el español don Bernardo Álvarez Anillo acreditando su conducta durante el interregno revolucionario y pidiendo se le restituyera a su antiguo empleo como director de la Real Fábrica de Aguardientes de Santa $\mathrm{Fe}$, además de lo cual clamó para que se le abonaran los sueldos adeudados desde cuando fue suspendido de su cargo. Luego de practicadas las diligencias y testimonios de rigor, el coronel Lucas González, juez fiscal del Consejo de Purificación, el 12 de agosto de 1816, con el visto bueno del general Pablo Morillo, emitió el respectivo certificado que absolvía a Álvarez Anillo de cualquier involucramiento en el gobierno revolucionario y al mismo tiempo se dispuso que debía ser objeto de una "completa indemnización". Desde el 20 de julio de 1810, fecha de inicio de las manifestaciones de autonomía política en la capital neogranadina, aquel funcionario se había retirado de todo servicio y se negó a recibir sueldos del "gobierno intruso", siéndole imposible emigrar por su deficiente estado de salud y por el peligro en los caminos. Aseguró este hombre nunca haber "desmentido el carácter de buen español y buen vasallo" y puso de presente los reiterados aportes a la causa del rey, entre los cuales destacó su participación en la construcción del puente de Villeta y la entrega de algunos donativos que sumaban en total 2420 pesos, siendo el más reciente el aporte de 220 pesos para el sostenimiento del ejército expedicionario ${ }^{13}$.

Las instalaciones del ramo, así como otras edificaciones de uso público, fueron utilizadas como cuarteles improvisados. Según relata en sus memorias José María Espinosa, abanderado patriota en la Campaña del Sur, al llegar a Cali a principios de 1814, pocos días después de la derrota sufrida en la ciudad de Pasto, se les entregó por cuartel el "hermoso edificio" de la fábrica de aguardiente ${ }^{14}$. En su diario, el cronista José María Caballero muestra cómo el 20 de mayo de 1815, en momentos en que la ciudad de Santa Fe se alistaba para defenderse de la invasión de las tropas españolas de Reconquista, el gobierno republicano mandó llevar dos cañones a la casa del estanco de aguardiente ubicado en la plazuela de San Francisco $^{15}$.

En medio del fragor de las guerras de independencia y del estado deficitario de las arcas oficiales, se recurrió con bastante frecuencia a los recursos de la renta de aguardiente para aliviar los enormes gastos militares. Esta apropiación de recursos se hizo la mayoría de

\footnotetext{
${ }^{11}$ Edward José Angulo Benítez, "Un corifeo patriota: el papel de don Manuel de Olalla en Iscuandé, 1801 1835" (tesis, Universidad del Valle, Cali, 2018), 84.

${ }^{12}$ Archivo Santander (Bogotá: Águila Negra Editorial, 1916), vol. II, 149-150.

${ }^{13}$ Archivo General de la Nación (AGN), Sección Colonia, Fondo Solicitudes, tomo 14, ff. 591r-606v.

14 José María Espinosa, Memorias de un abanderado. Recuerdos de la Patria Boba 1810-1819 (Bogotá: Imprenta de "El Tradicionalista", 1876), 96.

${ }^{15}$ Caballero, Particularidades de Santa Fe, 59.
} 
las veces de manera voluntaria, en otras bajo el mecanismo de la concertación, aunque en algunas ocasiones no se dudó en emplear la vía extrema de la intimidación. Sin embargo, la merma misma padecida por el ramo de aguardientes no siempre permitió atender cabalmente esas necesidades apremiantes.

Para animar las tripulaciones de los buques del apostadero del Puerto Real de Ocaña, a fin de que no siguieran desertando del servicio, el comandante español Valentín Capmani, el 31 de diciembre de 1815, ordenó al teniente Antonio Lanzas que a manera de incentivo repartiera entre aquellos militares 81 pesos recolectados del estanco de aguardientes de esta ciudad $^{16}$.

Durante estos años de Reconquista, el oficial Antonio Jiménez relató las dificultades experimentadas al querer disponer de 27.367 pesos que el gobierno virreinal había autorizado extraer de las rentas de la villa del Socorro para la paga de oficiales y el presupuesto de la tropa allí acantonada en los meses de septiembre y octubre de 1817 . Pese a los reiterados reclamos ante el gobernador, al cabo de un año apenas habían desembolsado 4910 pesos debido a que los productos arrojados por la administración de aguardiente eran muy limitados o se les daban otros destinos, mientras que las rentas de alcabalas y tabacos también resultaban insuficientes. Se pidió entonces al virrey Juan Sámano su intervención para no dejar a estas tropas desamparadas de oportunos auxilios ${ }^{17}$.

Mateo Vicente Rey, alcalde de Cunday, informó al corregidor don José María de Mier y Terán sobre las hostilidades causadas por las guerrillas del Mosca Rodríguez a principios de 1819. Esta partida de "insurgentes" había amenazado y tomado prisionero a las principales autoridades y vecinos de esta parroquia, después de lo cual obligaron al estanquero de aguardiente a entregar el dinero perteneciente a la renta y a distribuir el restante entre la tropa $^{18}$.

Ante la crisis fiscal imperante, los estancos de aguardiente y tabaco significaron una apreciable fuente de recursos de apoyo para otros sectores de la economía impactados por los embates de la guerra. Prácticamente se constituyeron estas rentas en una especie de caja menor con disposición de fondos frescos e inmediatos para atender algunas emergencias.

En tiempos de la primera República Federativa, en diciembre de 1813, los gobernantes de Zipaquirá propusieron que la casa que antes servía de sede para la administración de aguardiente fuera acondicionada como nuevo local para la escuela del lugar, pues la edificación existente para este propósito educativo era un "pajar" con muchas incomodidades ${ }^{19}$.

\section{Las vicisitudes de la renta durante la primera fase republicana}

Sin lugar a dudas, uno de los mayores debates en materia económica registrados durante el periodo de independencia y los años iniciales de la República giró en torno a la liberalización de las rentas estancadas, una decisión de hondas repercusiones no solo económicas, sino también sociales y políticas.

Después de 1810, la centralización del manejo económico que había imperado hasta entonces desapareció temporalmente tras la ausencia del poder virreinal. Bajo el primer experimento republicano, se abrió paso a un nuevo esquema político basado en la irrupción

\footnotetext{
${ }^{16}$ Academia Colombiana de Historia, Archivo del General Miguel de La Torre, tomo XXII, 71-72.

${ }^{17}$ Los Ejércitos del Rey, tomo I (Bogotá: Biblioteca de la Presidencia de la República, 1989), 44-45.

${ }^{18}$ Los Ejércitos del Rey, tomo II, 282.

${ }^{19}$ AGN, Sección Archivo Anexo, Fondo Instrucción Pública, tomo 4, f. 533r.
} 
de Estados provinciales con autonomía política que conllevó también a manejar un cierto grado de autonomía fiscal, todo esto en medio de disensiones políticas internas entre la tendencia centralista y la corriente federalista.

Esa fragmentación del poder y enfrentamiento interno entre facciones republicanas ${ }^{20}$ se constituyó en un punto de debilidad en el propósito por fortalecer una nueva nación independiente. Paralelamente a estas disputas políticas acentuadas por las rivalidades entre provincias, se llevaron a cabo operaciones militares tendientes a aniquilar la resistencia española que permanecía viva en las provincias de Santa Marta, Popayán y Pasto ${ }^{21}$. En estas zonas la guerra fue intermitente, pues ni las fuerzas patriotas ni las españolas lograron triunfos absolutos. Allí en donde aún permanecía el aparato de gobierno español permaneció vigente el sistema fiscal y tributario colonial.

Todas o la mayor parte de las juntas de gobierno erigidas durante esta época decidieron abolir los estancos de aguardiente y tabaco ${ }^{22}$ y el tributo de los indios. Con esta trascendental medida los dirigentes del naciente proyecto republicano buscaron congraciarse con el pueblo ${ }^{23}$, pero al no sustituirse estas fuentes de ingreso, se creó un hueco fiscal que debilitó ostensiblemente la economía ${ }^{24}$.

Tan pronto se registraron en la ciudad de Cartagena las primeras expresiones de autonomía política, el consulado exigió el cambio de sistema por uno de liberalización del mercado con miras a fomentar la agricultura y el comercio ${ }^{25}$. Entre tanto, Miguel Pombo, fiscal de la Junta Suprema de Santa Fe, pronunció en 1811 un discurso político en el que manifestó la necesidad de extinguir la renta de aguardiente ${ }^{26}$.

Otra de las Juntas Provinciales en inclinarse por la vía de la liberalización de la renta fue la de Antioquia ${ }^{27}$ en decisión asumida en septiembre de 1810:

Atendiendo a la reclamación general contra los ramos estancados de aguardiente y tabaco, principalmente a los de esta provincia, que por muchos años ha sido vejada con el duplo de sus valores, a las trabas que esto pone a la agricultura, a las noticias que se tienen de que las provincias donde se cosechaba el tabaco, con la exclusión que demandaban las factorías, lo han declarado de libre comercio, y que esto nos pone en el riesgo de no recibir las abundantes provisiones de que hasta ahora hemos disfrutado [...] se acuerda en beneficio de estos pueblos y en fomento de la agricultura e

\footnotetext{
${ }^{20}$ Anthony McFarlane, “La construcción del orden político: la 'Primera República' en la Nueva Granada, 18101815", Historia y Sociedad 8 (2002): 73.

21 Armando Martínez Garnica, "La desigual conducta de las provincias neogranadinas en el proceso de la Independencia", Anuario de Historia Regional y de las Fronteras 14, n. ${ }^{\circ} 1$ (2009): 37-54.

${ }^{22}$ Quito ya había marcado la pauta al tomar esta decisión en 1809 por parte de su Junta Suprema de Gobierno. José Manuel Restrepo, Historia de la Revolución de la República de Colombia, tomo segundo (París: Librería Americana, 1827), 112, 150. Una de las primeras determinaciones de la Junta Provincial creada en agosto de 1810 en Popayán fue abolir el estanco de aguardiente. Santiago Arroyo, Apuntamientos sobre la Revolución de la Nueva Granada, especialmente con respecto a la provincia de Popayán (Popayán: Fundación Caucana, 2010), 56.

${ }^{23}$ Ana Catalina Reyes, "El derrumbe en la primera república en la Nueva Granada entre 1810-1816”, Historia Crítica, n. ${ }^{\circ} 41$ (2010), 50.

${ }^{24}$ José Manuel Restrepo, Historia de la Revolución, tomo segundo, 210.

${ }^{25}$ Escritos de dos economistas coloniales (Bogotá: Banco de la República, 1965), 207.

${ }^{26}$ BNC, Fondo Manuscritos, tomo 184, ff. 189r-197v.

${ }^{27}$ Sobre el desarrollo del ramo de aguardiente en esta provincia, véase: Eliana Maritza Gómez Rodríguez, "De la destilación doméstica artesanal a la tecnificación de la producción del aguardiente: cultura material del aguardiente en Antioquia, 1736-1810", Pensar Historia, n. 5 (2014): 9-40.
} 
industria, que los expresados ramos de aguardiente y tabaco queden y sean en lo sucesivo de libre comercio, pudiéndose cosechar, destilar y consumir dentro de la provincia ${ }^{28}$.

Reconociéndose que la mayor parte de los ingresos públicos provenían de los ramos de aguardientes y tabacos, en aras de conseguir recursos para suplir esta falta, se acordó que todo vecino libre mayor de 18 años debía, sin distingo de género o condición social, hacer anualmente una pequeña contribución de 8 reales "por la franquicia que se le concede en el uso de estos ramos". Aquellos que se rehusaran a entregar estos aportes, serían sancionados con el duplo de aquel valor ${ }^{29}$.

En esta misma provincia, el 6 de junio de 1812 se dictó una ley para gravar a los destiladores de aguardiente con un impuesto que estaría destinado a suplir las necesidades del Estado ${ }^{30}$. Sin embargo, el 23 de octubre del año siguiente el presidente dictador Juan del Corral restableció el estanco y, una semana más tarde en la presentación de su informe de gestión, estos fueron los argumentos que lo habían convencido para optar por esta decisión:

Los notables desórdenes de una porción considerable del pueblo por el abuso de esta bebida, la falta de una exacta policía para la continencia, la prostitución de las costumbres, la ruina de las familias, el abandono de la agricultura y los oficios y la alteración general de la salud pública ${ }^{31}$.

A principios de 1814 se reportó cómo esta restitución del ramo había producidos buenos resultados, aunque todavía se avanzaba en el proceso del restablecimiento por cuanto la fábrica principal no alcanzaba a abastecer a los pueblos más remotos como Cáceres, Zaragoza y San Bartolomé, tarea que implicaba altos costos. Ante esta situación, se decidió que en aquellos lugares se rematara por asientos su administración, medida que, aunque no produjera considerables ingresos en su introducción, se esperaba que con el tiempo y con el celo y el trabajo de los arrendadores se arrojaran a futuro mayores dividendos ${ }^{32}$.

En este año, 1814, antes de su intempestivo fallecimiento, Corral alcanzó a fijar algunas medidas para que los administradores principales pudieran intervenir en las causas por fraude ${ }^{33}$. A partir de allí y durante los meses siguientes, el gobierno provincial emprendió una intensa campaña para combatir esta práctica ilegal siendo enjuiciadas al menos 10 personas. Así, por ejemplo, en junio de 1814 se abrió una sumaria contra Joaquina y Manuel Herrón ${ }^{34}$.

El 4 de enero de 1812 el cabildo de la villa de San Gil pidió anexarse a la provincia de Cundinamarca, en esta provincia se habían extinguido los estancos de aguardiente y tabaco, pero aún subsistía en San Gil el cantón del aguardiente porque el pueblo así lo

\footnotetext{
${ }^{28}$ Actas de formación de juntas y declaraciones de Independencia (1809-1822). Reales Audiencias de Quito, Caracas y Santa Fe, Bucaramanga, Universidad Industrial de Santander, 2008, tomo II, 217-218.

${ }^{29}$ El Argos Americano. Papel político, económico y literario de Cartagena de Indias, n. ${ }^{\circ}$ 7, octubre 29 de 1810 , 27.

${ }^{30}$ Archivo Histórico de Antioquia (AHA), Sección Independencia, Fondo Gobernación de Antioquia, tomo 824, ff. $160 \mathrm{r}-174 \mathrm{v}$.

${ }^{31}$ Roberto María Tisnés Jiménez, Don Juan del Corral. Libertador de los esclavos (Bogotá: Banco Popular, 1980), 399.

32 Tisnés Jiménez, Don Juan del Corral..., 429.

${ }_{33}$ AHA, Sección Independencia, Fondo Gobernación de Antioquia, tomo 828, ff. 157r-167r.

34 AHA, Sección Independencia, Fondo Gobernación de Antioquia, tomo 1021, ff.10r-16v. Sobre esta problemática en la provincia de Antioquia véase el trabajo: Eliana Maritza Gómez Rodríguez, "Entre lo ilegal, lo ilícito y lo consensuado: una historia del aguardiente en Antioquia, 1760-1814" (tesis, Universidad de Antioquia, 2014), 48-94.
} 
reclamaba y porque era el ramo más productivo para los gastos públicos. La idea era restablecer este ramo ya fuera por remate o por administración, según lo que se estimara más conveniente y consultando el beneficio de esta medida en el erario y en la comunidad ${ }^{35}$.

Desde luego, las órdenes de supresión del estanco afectaron a muchos empleados que llevaban una larga trayectoria en este negocio. Uno de esos damnificados fue José Antonio Arcos, quien en agosto de 1811 pidió a la Junta Superior de Gobierno de la provincia de Popayán que se le socorriera por haber quedado cesante tras la supresión de la Real Fábrica de Aguardientes en la que sirvió durante más de 21 años. En este caso, los oficiales reales optaron por socorrer a Arcos y a su familia para aliviarlo de sus precariedades económicas ${ }^{36}$. A principios de 1813 en Quilichao, población ubicada en esa misma provincia, se aprobó la solicitud elevada por los empleados de los extinguidos ramos de aguardiente y tabaco para que se les siguiera consignando su salario hasta que se les ubicara en un nuevo cargo público. Al final, se nombró a uno de ellos en el ramo de la alcabala ${ }^{37}$.

En resumidas cuentas, lo que se observa durante este primer experimento republicano es un deterioro de los ingresos fiscales, buena parte de los cuales estaba enfocado en el gasto militar $^{38}$. No pudo aplicarse de manera sistemática la política de liberalización del ramo por cuanto las autoridades a nivel provincial se percataron de las implicaciones fiscales de esta medida y, por ello, se observó en ciertos casos el intento por retornar al modelo de injerencia estatal o por explorar algunas fórmulas mixtas en el manejo de este sector. Era esto un claro recordatorio de la compleja realidad económica provincial y de la dificultad para borrar de tajo el modelo fiscal y tributario colonial que venía funcionando desde hacía ya varias décadas ${ }^{39}$.

\section{Reconquistar el poder y restaurar la renta}

Uno de los retos claves de los españoles para asegurar su dominio durante el periodo de Reconquista consistió en retomar el control de la economía tal como estaba antes de los hechos revolucionarios de 1810. Esto implicaba reimplantar los monopolios estatales y centralizar el control de los impuestos, todo con miras a generar ingresos con los cuales mantener la estructura administrativa y cubrir los considerables costos que acarreaba la defensa militar ${ }^{40}$. En algunos casos, como ocurrió en la provincia de Antioquia, el restablecimiento del estanco de aguardiente vino acompañado de una más frondosa estructura burocrática $^{41}$.

No obstante, si bien es cierto que el ejército expedicionario español consiguió de manera vertiginosa la reconquista militar del territorio, por otro lado, no fue tan fácil restablecer el antiguo esquema administrativo del ramo de aguardientes ni mucho menos recuperar su ritmo productivo. Inocultables eran ya en esta coyuntura de cambio de gobierno

\footnotetext{
${ }^{35}$ Archivo Nariño, tomo III, (Bogotá: Biblioteca de la Presidencia de la República, 1990), 76.

${ }^{36}$ Archivo Central del Cauca (ACC), Sección Independencia, signatura 37, Civil I-2 gobierno, ff. 1r-3v.

${ }^{37}$ ACC, Sección Independencia, signatura 208, Civil I, 2 gobierno, ff. 1r-2v.

38 José Joaquín Pinto Bernal y James Vladimir Torres Moreno, “Guerra y fisco en la Nueva Granada, 18111824”, Revista de Economía Institucional, 18, n. ${ }^{\circ} 35$ (2016): 187.

${ }^{39}$ Luis Eduardo Nieto Arteta, Economía y cultura en la historia de Colombia (Bogotá: Banco de la RepúblicaEl Áncora Editores, 1996), 60.

${ }^{40}$ Rebecca Earle, España y la Independencia de Colombia, 1810-1825 (Bogotá: Ediciones Uniandes-Banco de la República, 2104), 115-122.

${ }^{41}$ Rodrigo Campuzano Cuartas, "El inicio de la Reconquista en Antioquia", en Política, guerra y cultura en la Independencia de Antioquia, Rodrigo Campuzano Cuartas (director académico) (Medellín: Academia Antioqueña de Historia, 2013), 250.
} 
los estragos de la guerra por cuenta no solo de las luchas intestinas entre facciones políticas, sino por las frustradas operaciones militares de los independentistas por expulsar a los realistas del norte y del sur de la Nueva Granada. Aquella polarización política interna, avivada por rivalidades autonomistas y sectarias entre provincias e incluso entre localidades ${ }^{42}$, de algún modo trastocó el mapa político administrativo colonial y los flujos comerciales y económicos que venían operando hasta antes de que irrumpieran las primeras manifestaciones revolucionarias.

Lo que revelan los informes oficiales es que las medidas económicas del restaurado gobierno monárquico fueron promulgadas sin pausa, inmediatamente después de la ocupación militar. El 8 de mayo de 1815, cuando apenas el ejército expedicionario al mando del general Pablo Morillo iniciaba su invasión por la costa Caribe, el virrey Francisco de Montalvo impartió una serie de instrucciones al comandante Ignacio de la Rus al momento en que retomaba el dominio sobre la villa de Mompós con las tropas de Reconquista. Una de ellas consistía en incautar los fondos que hubiere en los ramos de aguardiente y tabaco administrados por el gobierno republicano. Todo debía inventariarse y guardarse meticulosamente hasta que fueran nombrados dos oficiales Reales que se encargaran de estos ramos que debían estancarse con miras a garantizar el sostenimiento de la división que sería acantonada en aquella villa. El aguardiente producido por los particulares no debía confiscarse, sino que debía comprarse por su precio justo ${ }^{43}$.

A través de una circular, Montalvo ordenó, el 30 de noviembre de 1815 en Cartagena, que a las destilerías privadas se les permitiera de manera temporal establecer contratos individuales con el gobierno para producir aguardiente. No obstante, el 11 de mayo del año siguiente se restableció el sistema de estancos, se prohibió la producción particular y se nombró un jefe administrativo, y el recién nombrado gobernador Gabriel de Torres ordenó a los hacendados reactivar el cultivo de caña de azúcar e impuso penas para quienes incurrieran en fraudes y contrabando ${ }^{44}$. Tal parece que estas medidas resultaron inocuas por cuanto para el 11 de junio de 1816 ningún productor se había presentado ante el gobernador Torres y había sido imposible controlar la producción ilegal debido a la falta de funcionarios de aduanas. Además de esto, la importación de aguardiente peruano había contraído ostensiblemente las ventas internas y en Cartagena los elementos para destilar se hallaban destruidos y debieron ser reemplazados ${ }^{45}$.

A finales de enero de 1818, al momento de entregar su cargo, el virrey Montalvo dejó un balance de su gestión a su sucesor Juan Sámano. Allí se observaba un contraste en el estado de la renta en cada una de las provincias.

En realidad, la reactivación del ramo fue muy lenta y con innumerables tropiezos que hacían más complicado seguir cabalmente las instrucciones virreinales en su afán por retomar nuevamente el control y la centralización de este sector de la economía. Así, por ejemplo,

\footnotetext{
${ }^{42}$ Sobre estas rivalidades cabe recordar aquellas suscitadas entre las provincias de Santa Marta a favor de la causa monárquica y Cartagena proclive a las banderas independentistas. También se registraron conflictos entre Cali y Popayán en el sur y entre San Gil y Socorro en la franja nororiental. Fernán González, Luis Horacio López Domínguez y Roger Pita Pico, El Bicentenario de la Independencia de Colombia 2019 y los retos de la celebración. Un encuentro en torno a las nuevas corrientes historiográficas, vol. I (Bogotá: Academia Colombiana de Historia, 2018), 187-283.

${ }^{43}$ Manuel Ezequiel Corrales, Documentos para la historia de la provincia de Cartagena de Indias, tomo segundo (Bogotá: Imprenta de Medardo Rivas, 1883), 57.

${ }^{44}$ AHA, Fondo Gobernación de Antioquia, tomo 850, f. 371r.

${ }^{45}$ Earle, España y la IndependenciaI..., 125.
} 
bastantes escollos se registraron al momento de conseguir funcionarios idóneos, muchos de los cuales habían estado involucrados en los agites de la revolución mientras que, en cuestiones operativas, había que resolver asuntos claves como lo era la costosa y complicada recuperación y adecuación de los elementos indispensables para la labor de destilación, siendo además cada vez más difícil mitigar los elevados niveles de ilegalidad y contrabando. Otro factor en contra era que el sistema de renta de aguardiente no dispuso de fondos suficientes para lograr la anhelada reactivación ${ }^{46}$.

Tal como se verá en los apartes del informe rendido por Montalvo, en algunas provincias fueron prácticamente nulos los avances por impulsar el ramo. A todo esto, se le sumaba el inconformismo popular derivado del carácter represivo de la campaña de Morillo y de la implantación oficial de alternativas de financiación como las confiscaciones, las contribuciones forzosas y los empréstitos ${ }^{47}$. Al mismo tiempo, crecían la incertidumbre y la desconfianza ante las noticias sobre la nueva ofensiva patriota que paso a paso empezaba a gestarse en las zonas del interior y en los Llanos Orientales.

El informe abre con un diagnóstico sobre la fábrica de aguardientes de Santa Fe, respecto de lo cual se hizo énfasis en la necesidad de conseguir 6.000 pesos para comenzar las destilaciones, repararse del todo y producir los mismos fondos generados antes de la revolución. Por eso, la recomendación que hacía Montalvo era autorizar el desembolso de las cajas reales para este propósito en el entendido de que todo esto redundaría en crecidas utilidades para el erario, además de lo cual se consideraba clave nombrar un administrador de renombrada experiencia.

En cuanto a la administración de la villa de Honda, los informes señalaban que se hallaba en tal estado de ruina que era imposible restablecerla sin que acarreara elevados costos, que al momento no podía cubrir la Real Hacienda, a todo lo cual se sumaba el hecho de que el administrador don Bernardo Rodríguez era un hombre ya avanzado en años y en enfermedades que le impedían atender cabalmente sus responsabilidades. Ante tantos inconvenientes para reorganizar esta fábrica, el Contador sugirió que se subastara la renta para ponerla en arriendo.

En Mompós el antiguo contador de la administración de aguardiente de Cartagena había propuesto restablecer la renta instalando allí una fábrica provisional cuyos productos se destinarían a dicho objeto y a la compra de los insumos indispensables. A él se le prometieron enviar algunos alambiques de la fábrica de Cartagena y debían además implementarse medidas inmediatas para impedir las destilaciones por parte de particulares. En agosto de 1817 se aceptó la propuesta con el compromiso de que al año siguiente debía estar lista la fábrica.

Respecto a la administración de Cartagena el panorama general presentado por Montalvo era menos sombrío. Tras la abolición del ramo durante el tiempo en que gobernaron los "insurgentes", los alambiques y demás elementos habían desaparecido, unos vendidos y otros en manos de particulares. Ante esto, se solicitó a Bernardo Rodríguez el restablecimiento de esta administración, siendo su primera tarea recuperar aquellos elementos perdidos, pero al final fueron infructuosos sus esfuerzos. Hubo necesidad de reemplazar a este hombre y en su lugar asumió funciones don José María de la Terga,

\footnotetext{
46 Justo Cuño Bonito, El retorno del Rey. El restablecimiento del régimen colonial en Cartagena de Indias (1815-1821) (Castello de la Plana: Universitat Jaume, 2008), 160.

${ }^{47}$ Ejemplo de ello fue la contribución exigida en 1817 en Simití de 17.500 pesos, destinándose parte de estos recaudos para el restablecimiento de la fábrica de aguardientes en Mompós. Cuño, El retorno del Rey..., 151.
} 
empleado experimentado que logró finalmente la reorganización de esta renta al producir a fecha del 31 de octubre de 1817 un total de 82.569 pesos y de recursos propios 29.874 pesos sin comprometer ningún gasto adicional de las reales cajas. Esto, sumado a las utilidades de la también restituida renta de tabaco, representaba para la administración del entrante virrey Sámano un holgado fondo para financiar la guarnición de esta plaza. Para 1818 el gobierno provincial emitió algunas medidas para evitar la destilación clandestina detectada en Cartagena y Corozal $^{48}$.

La fábrica de Santa Marta ${ }^{49}$, pese a que se había restablecido en 1814, no reflejaba el mismo impulso que la de Cartagena, observándose una baja en sus productos pues en el primer semestre de 1817 solo habían entrado por este concepto a las cajas reales 1.327 pesos, una cifra irrisoria frente a los más de 20.000 pesos que producía anualmente entre 1806 y 1809. Sobre esta situación el ayuntamiento de la ciudad aclaró que, aunque las haciendas de caña estaban en favorable capacidad productiva, la principal causa del declive era la falta de control a las destilaciones clandestinas y a la introducción de licores foráneos. Al requerírsele un informe, el administrador Rafael Sánchez arguyó la escasez de mieles y anís, así como también el desmonte frecuente de los alambiques por su mal estado. Ante estas explicaciones, el virrey Montalvo adoptó los correctivos necesarios y elevó cargos contra el administrador por algunos abusos cometidos.

En Riohacha no se había cumplido la orden del anterior virrey Antonio Amar y Borbón de establecer allí una administración particular. Montalvo impartió instrucciones para que la fábrica de Santa Marta le proveyera temporalmente a Riohacha el producto y que, asegurado el abastecimiento, cesara la introducción de licores extranjeros por ese punto. Sin embargo, a enero de 1819 aún no había sido posible cumplir este propósito ${ }^{50}$. La administración de Panamá tampoco estaba organizada y se sugirió aunar esfuerzos para instalar allí una fábrica no sin antes implementar acciones tendientes a prohibir la introducción de aguardientes del Perú, que abundaban en aquel istmo ${ }^{51}$.

Teniendo como experiencia las problemáticas ya vividas y, ante la imposibilidad de restablecer el estanco en los niveles productivos alcanzados antes del inicio del periodo de independencia, algunos sectores oficiales no se mostraban tan convencidos de continuar con este sistema de proteccionismo estatal, una discusión que se extendería hasta las postrimerías del dominio monárquico.

Estas diferentes posturas de los gobernantes y agentes fiscales, enmarcadas en cierto modo por el impulso de la corriente liberal en España, provocó fisuras que contribuyeron a debilitar el agónico régimen monárquico, registrándose en algunos casos fuertes discordias como aquella registrada entre el virrey Francisco Montalvo ante las continuas intromisiones del general Pablo Morillo en asuntos de gobierno y economía ${ }^{52}$. Las vacilaciones sobre el rumbo de la economía también se sintieron en Madrid, sede del imperio.

\footnotetext{
${ }^{48}$ AGN, Sección Colonia, Fondo Aguardientes de Bolívar, tomo 6, ff. 660r-679v.

${ }^{49}$ En Santa Marta, los ingresos arrojados por el estanco de tabaco y aguardiente representaban el $50 \%$ de los ingresos fiscales, entre 1797 y 1815. Joaquín Viloria de la Hoz, "Santa Marta Real y Republicana: el accionar económico y político de la provincia de Santa Marta", Cuadernos de Historia Económica y Empresarial, n. ${ }^{\circ}$ 36 (2015), 59.

${ }^{50}$ AGN, Sección Archivo Anexo II, Fondo Administración de Aguardientes, Serie Administraciones-Informes, caja 26, carpeta 2, ff. 24r-53v.

${ }^{51}$ Colmenares, Relaciones e Informes..., 310-315.

${ }^{52}$ Marcela Echeverri, Esclavos e indígenas realistas en la Era de la Revolución. Reforma, revolución y realismo en los Andes septentrionales, 1780-1825 (Bogotá: Universidad de Los Andes-Banco de la República, 2018),
} 
Dentro de las recomendaciones formuladas en junio de 1817 por el comandante en jefe español Pablo Morillo para mejorar el manejo administrativo y económico del territorio neogranadino, se encontraba el desestanco del tabaco y del aguardiente como "un nuevo manantial de riquezas", pues en ese momento la recaudación de estos ramos no pasaba del 5 $\%$ del total de los ingresos. Sin embargo, consideró que, por su falta de experiencia en esta materia, no le correspondía diseñar un plan económico y por ello creyó necesario que este asunto lo tratara con tino el gobierno de la península con miras a mejorar este ramo en América. La idea con este desestanco era fomentar la extracción de estos productos con lo cual se podría cubrir el déficit de los gastos anuales "con un reparto o con algún otro arbitrio que no obstruya los progresos de la agricultura"53.

Por su parte, el gobernador de la provincia de Cartagena don Gabriel de Torres denunció en marzo de 1819 el estado crítico de su territorio por la falta de moneda circulante y el abatimiento de la agricultura y del comercio. Los cultivadores se hallaban sin recursos, las haciendas sin mano de obra ni herramientas, pues apenas algunos propietarios se dedicaban a sembrar caña y producir mieles a pequeña escala con el fin de destinarlas a la fábrica de aguardiente ${ }^{54}$, pero las utilidades apenas les servían para mantener a sus familias y eso cuando no experimentaban demora en los pagos por causa del corto expendio del licor, ante lo cual cada vez iban en aumento sus deudas que habían obligado a varios de ellos a ceder o vender sus negocios 55 .

A mediados de julio, al momento en que este gobernador exponía ante el rey la generalizada crisis económica que padecía su provincia, insistía en que el sistema de estancos era el establecimiento más perjudicial para el real erario y para la agricultura, una situación que ya el Monarca conocía pues había mandado extinguir el estanco en algunos lugares del imperio. Consideraba Torres que no había nada más ruinoso que vedar el libre cultivo de la caña y la comercialización del licor:

Casi toda la agricultura de esta provincia está reducida a pequeñas plantaciones de algodón y caña, pero esta segunda, no pudiendo nadie destilar aguardiente ni teniéndoles cuenta elaborar azúcar, se halla sin el menor fomento, pues obligados los labradores a contratarla en pequeña cantidad con la renta de aguardientes, o tienen que vender la excedente a un precio ínfimo, en cuyo caso son ellos perjudicados, o emplearla en destilaciones clandestinas, causando incalculable perjuicio a las rentas de vuestra majestad. Este, señor, es el vicio radical de que adolece este ramo de agricultura, al cual, agregado el monopolio de los que administran la renta, retraso en los pagos, vejaciones sin número en las compras, teniendo que perder los labradores muchas veces las cosechas y otros infinitos males, de aquí resulta en su mayor parte la miseria en que yace esta provincia. Yo me atrevo a pronosticar, sin temor de engañarme, que sólo el desestanco del aguardiente produciría incalculables aumentos al real erario y felicidad a los labradores, que bendecirían la mano protectora de vuestra majestad, reconociendo en este rasgo el carácter paternal de su soberano ${ }^{56}$.

38. Daniel Gutiérrez Ardila, La Restauración en la Nueva Granada (1815-1819) (Bogotá: Universidad Externado de Colombia, 2016), 137-143.

${ }_{53}^{3}$ Antonio Rodríguez Villa, El teniente general don Pablo Morillo. Primer Conde de Cartagena, Marqués de la Fuerte (1778-1837), tomo III (Madrid: Tipografía de Fortanet, 1910), 309-322. Juan Friede, La otra verdad. La Independencia americana vista por los españoles (Bogotá: Tercer Mundo, 1972), 31.

${ }^{54}$ Según las cuentas de la tesorería de la Real Hacienda de Cartagena, el rubro del estanco de aguardientes representaba el 4,7\% del total de ingresos mientras que el del tabaco se ubicaba en $16 \%$. Adolfo Meisel Roca, "La crisis fiscal de Cartagena en la era de la Independencia, 1808-1821", en Cartagena de Indias en la independencia, Haroldo Calvo Stevenson y Adolfo Meisel Roca (Cartagena: Banco de la República, 2011), 397.

${ }_{55}^{55}$ Los Ejércitos del Rey, tomo II..., 18-19.

${ }^{56}$ Los Ejércitos del Rey, tomo II..., 294. 
El cabildo de la ciudad se sumó a este clamor para desregular el negocio del aguardiente tras argüir que había causado "males incalculables" a la provincia. Lo cierto es que las cifras denotaban de alguna manera estas fluctuaciones pues en 1816 este ramo en la provincia de Cartagena había producido tan solo 600 pesos y en 1818 se generó un ingreso neto de 8.000 pesos, pero de todos modos esta cifra estaba todavía muy lejana de alcanzar los 40.000 o 50.0000 pesos obtenidos en los años anteriores al periodo de guerra. A este panorama se sumaban situaciones como la ocurrida en Chiriguaná en donde se infringía la ley monopólica pues todo el aguardiente era producido por destilerías particulares clandestinas, situación que sucedía bajo la mirada indiferente de los funcionarios locales ${ }^{57}$.

En términos generales, al término del gobierno de Reconquista la situación de la economía neogranadina no era muy alentadora por cuanto había resultado imposible reactivar el nivel de ingresos con base en la producción del oro, los estancos y los impuestos mientras que el comercio y los bienes confiscados no arrojaban las cifras esperadas. A todo esto, se le sumaba la denuncia del virrey Montalvo sobre el desorden en el manejo de los caudales ${ }^{58}$.

En agosto de 1819 los españoles experimentaron una contundente derrota tras la ocupación de la ciudad de Santa Fe por parte de las fuerzas republicanas después del triunfo obtenido en la batalla de Boyacá. En el informe que presentara el 25 de septiembre de 1819, el fiscal de la Real Audiencia don Agustín de Lopetedi reflexionó sobre la multiplicidad de causas que habían precipitado esta pérdida, siendo una de ellas el estrepitoso aumento en los precios del aguardiente. Pensaba Lopetedi que hubiese sido un alivio si el rey, después de haber requerido los correspondientes estudios técnicos, hubiese tomado de manera oportuna la decisión de desestancar los ramos de aguardiente y tabacos, lo cual de seguro hubiera contribuido eficazmente al fomento a la agricultura y a la reactivación del comercio. Lamentaba aquel alto funcionario la lentitud con la que se abordó dicho estudio pues ni siquiera se había enviado a la Junta Superior de la Real Hacienda para adoptar medidas inmediatas $^{59}$.

\section{Conclusiones generales}

Las dificultades económicas causadas por las guerras de independencia en la Nueva Granada afectaron amplios sectores de la economía, incluso el ramo de aguardiente cuyas utilidades jamás superarían las registradas antes de 1810 bajo el esquema del estanco. De esta forma, para los primeros años de la República y luego de haberse constituido en un fondo extraordinario para las necesidades acuciantes de los gobiernos de turno, este rubro perdería su peso en la economía mientras que el tabaco adquirió mayor preponderancia no solo a nivel interno, sino en cuanto a sus potencialidades de comercialización externa.

El desarrollo de la renta de aguardientes se vio afectado por los continuos cambios administrativos y de gobierno, así como también por las fluctuaciones en la legislación sobre esta materia. Para comprender mejor los avatares de este ramo es necesario tener presente la conexión entre las dinámicas de la guerra y el fisco, y su impacto en cada una de las provincias $^{60}$. En estos años se mantuvo vivo el debate entre los principios liberales

\footnotetext{
${ }^{57}$ Earle, España y la Independencia..., 126-127.

${ }^{58}$ Earle, España y la Independencia ..., 114-122. Colmenares, Relaciones e Informes..., 286-296.

${ }^{59}$ Corrales, Documentos para la historia..., 384.

${ }^{60}$ Pinto y Torres, “Guerra y fisco en la Nueva Granada, 1811-1824”, 184.
} 
promovidos por el nuevo régimen republicano y el modelo económico proteccionista aplicado durante más de dos siglos por el gobierno español.

Las diferentes tendencias y los avances contrastantes en cada una de las regiones en cuanto al ramo de aguardientes fueron factores determinantes para que, más que hablar de cambios radicales durante el periodo de independencia y los primeros años de vida republicana, se observara más bien una compleja dinámica que implicó continuidades y reacomodamientos, según las circunstancias del momento. Si bien el sistema fiscal experimentó algunos cambios en este periodo de transición, siguieron persistiendo algunos rasgos coloniales como fue el caso del estanco ${ }^{61}$.

Los gobernantes eran conscientes de las implicaciones de las medidas que afectaban este ramo, recordatorio de lo cual era la revuelta comunera, y por ello actuaron con cautela pues temían que sus decisiones pudieran causar un desbordamiento del orden social que no era muy recomendable en estos tiempos de convulsión política y militar.

Durante todo este periodo, tanto para las autoridades republicanas como para las autoridades españolas fue una constante preocupación atacar los altos índices de fraude y contrabando en medio de unos frágiles mecanismos de control, factores estos que impidieron el progreso de la renta.

Durante la Segunda República, el propósito del gobierno fue recuperar la economía tras los estragos de una guerra cruenta y prolongada. Durante estos primeros años de vida independiente, de nuevo se reactivó la discusión sobre la organización del ramo de aguardiente, estableciéndose hacia 1821 la liberalización del ramo y, aunque se implementaron algunos ajustes normativos en $1824^{62}$, finalmente el presidente Simón Bolívar, investido ya de poderes dictatoriales, decidió restablecer el sistema de estanco.

\footnotetext{
${ }^{61}$ Luis Ospina Vásquez, Industria y protección en Colombia, 1810-1930 (Medellín: E.S.F., 1955), 187.
}

${ }^{62}$ David Bushnell, El Régimen de Santander en la Gran Colombia (Bogotá: El Áncora, 1985), 103. 


\section{Referencias}

\section{Fuentes primarias documentales}

Archivo Central del Cauca (ACC). Popayán-Colombia. Sección Independencia.

Academia Colombiana de Historia. Bogotá-Colombia. Archivo del General Miguel de La Torre.

Archivo General de la Nación (AGN). Bogotá-Colombia. Fondo: Aguardiente, Instrucción Pública, Miscelánea de la República, Negocios Administrativos, Secretaría de Guerra y Marina, Peticiones-Solicitudes, Solicitudes.

Archivo Histórico de Antioquia (AHA). Medellín-Colombia. Sección Independencia, Fondo Gobernación de Antioquia.

Archivo Histórico Cipriano Rodríguez Santa María (AHCRSM), Universidad de la Sabana. Bogotá-Colombia. Fondo Manuel María Mosquera.

Archivo Histórico Restrepo. Bogotá-Colombia. Fondo XIII.

Biblioteca Nacional de Colombia (BNC). Bogotá-Colombia. Fondos: Manuscritos, Pineda.

\section{Fuentes primarias impresas}

Actas de formación de juntas y declaraciones de Independencia (1809-1822). Reales Audiencias de Quito, Caracas y Santa Fe, tomo II. Bucaramanga: Universidad Industrial de Santander, 2008.

Archivo Nariño, tomo III. Bogotá: Biblioteca de la Presidencia de la República, 1990.

Archivo Santander. Bogotá: Águila Negra Editorial, 1916, vol. II, IV, VII.

Caballero, José María. Particularidades de Santa Fe. Bogotá: Biblioteca Popular de Cultura Colombiana, 1946.

Colmenares, Germán (Compilador). Relaciones e Informes de los Gobernantes de la Nueva Granada, tomo III. Bogotá: Biblioteca Banco Popular, 1989.

Corrales, Manuel Ezequiel. Documentos para la historia de la provincia de Cartagena de Indias, tomo segundo. Bogotá: Imprenta de Medardo Rivas, 1883.

El Argos Americano. Papel político, económico y literario de Cartagena de Indias. Cartagena, En la Imprenta de Diego Espinosa de los Monteros, 1810.

Escritos de dos economistas coloniales. Bogotá: Banco de la República, 1965. 
Espinosa, José María. Memorias de un abanderado. Recuerdos de la Patria Boba 1810-1819. Bogotá: Imprenta de "El Tradicionalista”, 1876.

Friede, Juan. La otra verdad. La Independencia americana vista por los españoles. Bogotá: Tercer Mundo, 1972.

Ley Fundamental de la República de Colombia. Angostura: [s.n.], 1819.

Los Ejércitos del Rey, tomo I y II. Bogotá: Biblioteca de la Presidencia de la República, 1989.

Restrepo, José Manuel. Historia de la Revolución de la República de Colombia, tomo segundo. París: Librería Americana, 1827.

Rodríguez Villa, Antonio. El teniente general don Pablo Morillo. Primer Conde de Cartagena, Marqués de la Fuerte (1778-1837), tomo III. Madrid: Tipografía de Fortanet, 1910.

\section{Fuentes secundarias}

Angulo Benítez, Edward José. "Un corifeo patriota: el papel de don Manuel de Olalla en Iscuandé, 1801-1835". Tesis. Universidad del Valle, Cali, 2018.

Arroyo, Santiago. Apuntamientos sobre la Revolución de la Nueva Granada, especialmente con respecto a la provincia de Popayán. Popayán: Fundación Caucana, 2010.

Bushnell, David. El Régimen de Santander en la Gran Colombia. Bogotá: El Áncora, 1985.

Campuzano Cuartas, Rodrigo. "El inicio de la Reconquista en Antioquia". En Política, guerra y cultura en la Independencia de Antioquia, Rodrigo Campuzano Cuartas (director académico), 223-256. Medellín: Academia Antioqueña de Historia, 2013.

Cuño Bonito, Justo. El retorno del Rey. El restablecimiento del régimen colonial en Cartagena de Indias (1815-1821). Castello de la Plana: Universitat Jaume, 2008.

De la Hoz, Joaquín Viloria. "Santa Marta Real y Republicana: el accionar económico y político de la provincia de Santa Marta”. Cuadernos de Historia Económica y Empresarial, n. ${ }^{\circ} 36$ (2015), 1-93.

Earle, Rebecca. España y la Independencia de Colombia, 1810-1825. Bogotá: Ediciones Uniandes-Banco de la República, 2104.

Echeverri, Marcela. Esclavos e indígenas realistas en la Era de la Revolución. Reforma, revolución y realismo en los Andes septentrionales, 1780-1825. Bogotá: Universidad de Los Andes-Banco de la República, 2018. 
Gómez Rodríguez, Eliana Maritza. "Entre lo ilegal, lo ilícito y lo consensuado: una historia del aguardiente en Antioquia, 1760-1814". Tesis. Universidad de Antioquia, Medellín, 2014.

- "De la destilación doméstica artesanal a la tecnificación de la producción del aguardiente: cultura material del aguardiente en Antioquia, 1736-1810". Pensar Historia, n. ${ }^{\circ} 5$ (2014).

González, Fernán, Luis Horacio López Domínguez y Roger Pita Pico. El Bicentenario de la Independencia de Colombia 2019 y los retos de la celebración. Un encuentro en torno a las nuevas corrientes historiográficas, vol. I. Bogotá: Academia Colombiana de Historia, 2018.

Gutiérrez Ardila, Daniel. La Restauración en la Nueva Granada (1815-1819). Bogotá: Universidad Externado de Colombia, 2016.

Martínez Garnica. "La desigual conducta de las provincias neogranadinas en el proceso de la Independencia". Anuario de Historia Regional y de las Fronteras 14, n. ${ }^{\circ} 1$ (2009): $37-54$.

McFarlane, Anthony. "La construcción del orden político: la 'Primera República' en la Nueva Granada, 1810-1815”. Historia y Sociedad 8 (2002): 47-82.

Meisel Roca, Adolfo. "La crisis fiscal de Cartagena en la era de la Independencia, 18081821”. En Cartagena de Indias en la independencia, Haroldo Calvo Stevenson y Adolfo Meisel Roca, 371-404. Cartagena: Banco de la República, 2011.

Mora de Tovar, Gilma Lucía. “Chicha, guarapo y presión fiscal en la sociedad colonial del siglo XVIII”, Anuario Colombiano de Historia Social y de la Cultura, n. ${ }^{\circ} 16-17$ (1988): 15-47.

Nieto Arteta, Luis Eduardo. Economía y cultura en la historia de Colombia. Bogotá: Banco de la República-El Áncora Editores, 1996.

Ospina Vásquez, Luis. Industria y protección en Colombia, 1810-1930. Medellín: E.S.F., 1955.

Phelan, John Leddy. La revolución Comunera en Colombia, 1781. Bogotá: Universidad del Rosario, 2009.

Pinto Bernal, José Joaquín y James Vladimir Torres Moreno. "Guerra y fisco en la Nueva Granada, 1811-1824”. Revista de Economía Institucional, 18, n. ${ }^{\circ} 35$ (2016): 171195. 
Pita Pico, Roger. "El consumo de bebidas embriagantes durante el proceso de Independencia de Colombia: aliento, festejo y conspiración”. Historia y Memoria, n. ${ }^{\circ} 7$ (2013): 227268.

Reyes, Ana Catalina. "El derrumbe en la primera república en la Nueva Granada entre 18101816”. Historia Crítica, n. ${ }^{\circ} 41$ (2010): 38-61.

Tisnés Jiménez, Roberto María. Don Juan del Corral. Libertador de los esclavos. Bogotá: Banco Popular, 1980. 